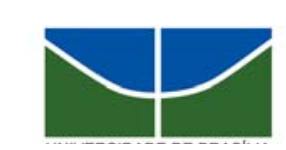

UNIVERSIDADE DE BRASÍLIA

Centro de Excelência em Turismo

Pós-graduação Lato Sensu

Curso de Especialização em Qualidade em Alimentos

\title{
CONVIVENDO COM O INIMIGO - COZINHA DOMICILIAR E RISCOS DE CONTAMINAÇÃO ALIMENTAR
}

\author{
Rafaela Nemer Xavier
}

Prof Dra Rita de Cássia Akutsu 


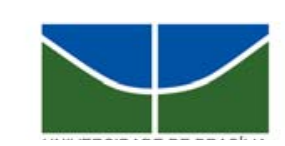

UNIVERSIDADE DE BRASÍLIA

Centro de Excelência em Turismo

Pós-graduação Lato Sensu

Curso de Especialização em Qualidade em Alimentos

\title{
CONVIVENDO COM O INIMIGO - COZINHA DOMICILIAR E RISCOS DE CONTAMINAÇÃO ALIMENTAR
}

\author{
Rafaela Nemer Xavier \\ Prof Dra Rita de Cássia Akutsu
}

Monografia apresentada ao Centro de Excelência em Turismo - CET, da Universidade de Brasília UnB, como requisito parcial à obtenção do grau de Especialista em Qualidade em Alimentos.

Brasília - 2009 
Nemer, Rafaela.

Convivendo com inimigo - Cozinha domiciliar e riscos de contaminação alimentar / Rafaela Nemer. - Brasília, 2009.

xvi, 42 f. : il.

Monografia (especialização) - Universidade de Brasília, Centro de Excelência em Turismo, 2009.

Orientador: Rita de Cássia Akutsu.

1. Convivendo. 2. Inimigo. I. Título. II. Título: Cozinha domiciliar e riscos de contaminação alimentar. 


\title{
UNIVERSIDADE DE BRASÍLIA
}

Centro de Excelência em Turismo

Pós-graduação Lato Sensu

Curso de Especialização em Qualidade em Alimentos

\author{
Rafaela Nemer Xavier
}

Aprovado por:

Prof $^{a}$. Dr ${ }^{\mathrm{a}}$ Rita de Cássia Akutsu

Prof $^{a}$. Dr ${ }^{\mathrm{a}}$ Karin Eleonora Sávio de Oliveira

\section{Professor:}

Brasília, 22 de abril de 2009. 


\section{DEDICATÓRIA}

A Deus por me dar o dom da vida e saúde para lutar pelos meus ideais.

À minha mãe que tornou meus sonhos de me profissionalizar e me especializar possíveis e que me incentiva a seguir a carreira acadêmica.

Ao colega de pós graduação, Raphael Valente, por gentilmente me ter cedido seu tema, espero que esteja como esperava. 


\section{AGRADECIMENTOS}

À professora Rita de Cássia Akutsu sempre dinâmica.

À minha querida ex - estagiária Mariana Camargo, técnica em nutrição e futura nutricionista de sucesso, pela ajuda não só na aplicação de alguns chek-list, mas também com carinho e atenção.

À Raquel Torres. Taíza Paiva, Marcus Jaculi e Sumara Alves pela amizade e por todos os inesquecíveis trabalhos em grupos que fizemos durante esta pós graduação, me acrescentaram muito pessoal e profissionalmente.

Finalmente, ao Marcelo Arruda, meu noivo, grande amor da minha vida, pelo seu amor incondicional, carinho, incentivo, companheirismo e por ter sido o grande facilitador para que esta monografia acontecesse, uma vez que estudou nutrição para poder auxiliar na monografia. 


\section{EPÍGRAFE}

"La destinée des nations dépend de la manière dont elles se nourrisent” (BRILLAT - SAVARIN, 1825) 


\section{RESUMO}

Objetivo: Identificar falhas higiênico - sanitárias no processo de produção de refeições domésticas utilizando o check - list baseado na RDC 275/ 2002. Métodos: A partir de uma seleção por conveniência, foram visitadas nove residências, sendo três pertencentes à classe econômica $\mathrm{A}$, três à classe econômica $\mathrm{B}$ e três à classe econômica $\mathrm{C}$. Após a compilação e análise dos dados, os resultados encontrados foram classificados como Grupo 1 (G1) com 76 a 100\% de atendimento, Grupo 2 (G2) com 51 a 75\% de atendimento e Grupo 3 (G3) com 0 a $50 \%$ dos itens atendidos, de acordo com a classificação disponibilizada no instrumento utilizado. Resultados: Os resultados obtidos em todos os domicílios visitados, sem subdividilos de acordo com a classe econômica a que pertencem, classificam as famílias como G3, pois estas atenderam a apenas 38\% das exigências da legislação. Após subdividir as famílias por classes econômicas, a classe econômica A foi classificada como G2, enquanto as famílias pertencentes às classes econômicas B e C foram classificadas como G3, sendo que a classe econômica $C$ apresenta menor percentual de atendimento às exigências da legislação. Conclusão: Os hábitos higiênicos para a manipulação de alimentos devem ser amplamente difundidos pela população, tanto pela televisão quanto pelas escolas. A inclusão de uma matéria que abranja tal assunto no currículo escolar de crianças e adolescentes poderia resultar em melhores procedimentos nos domicílios, tendo em vista que estes lidam melhor com mudanças de hábitos do que os adultos e idosos.

Palavras-chave: qualidade; contaminação alimentar domiciliar; boas práticas. 


\begin{abstract}
Objective: To indentify gaps at domestics' food fabrication process by applying the check list tool legalized by Brazil's National Agency for Sanitary Regulation, RDC 275/2002. Methods: From a convenience sample, nine residencies were visited, three of them belong to economic class A, three belong to economic class B, and the last three to economic class $\mathrm{C}$. After analyzing the data, the results found were classified as Group 1 (G1) with $76-100 \%$ of adaptation to the legislation demand, Group 2 (G2) with $51-75 \%$ of adaptation to the legislation demand, and Group 3 (G3) with $0-50 \%$ of adaptation to the legislation demand. This classification was provided by the check list tool of Brazil's National Agency for Sanitary Regulation. Results: The found results through all the residencies visited, without subdivide them according to the economic class that each of them belong, classify the all nine families as Group 3, once they demonstrate $38 \%$ of adaptation to the legislation demand. After subdividing the families according to the economic class they belong, the economic class A was classified as Group 2, and the families that belong to economic class B and C were classified as G3, but the class economic C families had the lower percentage of adaptation to the legislation demand. Conclusion: The knowledge of hygienic and sanitary control of food production should be spread through the entire population by television or school classes. By including a subject that teach such matter could lead to better sanitary control of food production at the residencies, once children and teenagers adapt to changes easier than adults and elderly.
\end{abstract}

Keywords: quality; domestic food contamination; good manners of food production. 


\section{LISTA DE TABELAS}

TABELA 1 - Percentual de adequação aos macro itens da RDC 275/2002 em domicílios do Distrito Federal -2009.

Tabela 2 - Análise vertical dos resultados obtidos a partir da aplicação check - list da RDC 275/2002 em nove residências do DF, no período de dezembro de 2008 a fevereiro de 2009. 


\section{SUMÁRIO}

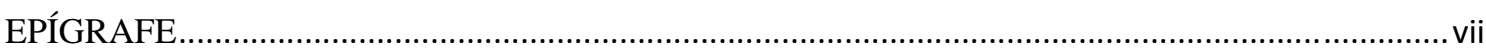

RESUMO …

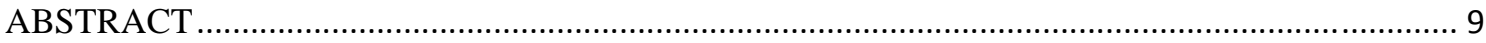

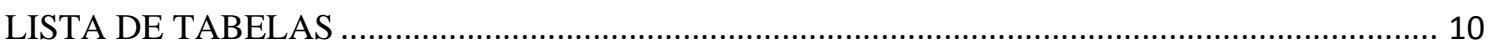

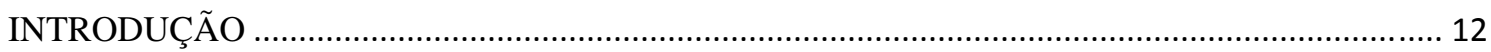

Boas Práticas de Fabricação de Alimentos ............................................................................... 13

Análises de Perigo e Pontos Críticos de Controle - APPCC ......................................................... 15

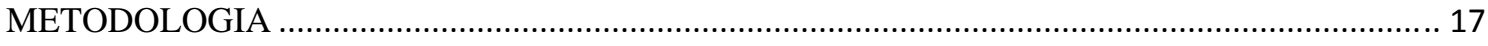

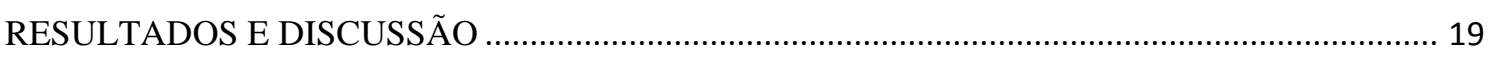

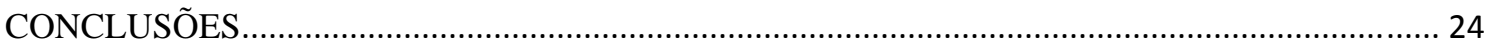

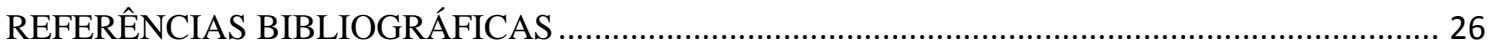

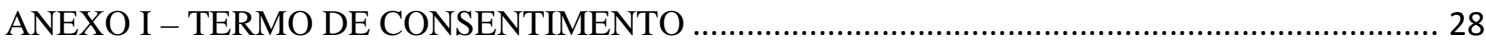

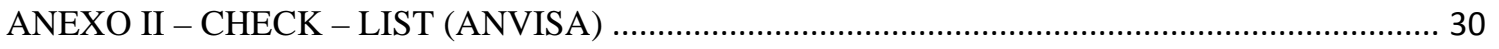




\section{INTRODUÇÃO}

A busca por qualidade não é um fato recente no mundo. Desde a década de 30 do século XX já se analisava os produtos finais a fim de identificar os defeituosos. Não é o mesmo conceito de qualidade, mas é uma demonstração da importância dada ao resultado final do processo de produção (LONGO, 1996).

Entende-se que um produto ou serviço de qualidade é aquele que atende perfeitamente, de forma confiável, acessível, segura e no tempo certo, às expectativas do cliente (BALSANELLI, 2005). Essa expectativa varia de acordo com as necessidades e experiências do cliente, ou seja, qualidade é um conceito conhecido por todos, mas é percebido de formas diferentes por cada um.

Tratando-se de alimentação, a percepção da qualidade não se limita apenas ao sabor, à aparência e outros fatores intrínsecos, hoje o controle higiênico - sanitário é imprescindível para atrair e fidelizar clientes (AKUTSU et al., 2005), uma vez que a não aplicação das boas práticas de fabricação pode acarretar diversos danos a saúde, tais como as toxinfecções. (ZANDONADI et al., 2007)

Em outras palavras, o alimento a ser consumido deve estar livre de contaminação microbiana, ter seus prazos de validade respeitados, tanto os dos alimentos preparados quanto os das matérias primas, ou seja, deve respeitar o direito do cidadão de se alimentar de forma digna. Alguns defensores desta idéia defendem inclusive a proibição do consumo de alimentos transgênicos (BELIK, 2003). Por fim, ao se avaliar a qualidade dos alimentos, é importante avaliar a satisfação de seus requisitos específicos; para tanto existem normas e padrões a serem respeitados (AKUTSU, 2005).

Para promover e normatizar as questões sanitárias vinculadas aos alimentos foi que em 1999, criou-se pela Lei no 9.782 de 26 de janeiro, a Agência Nacional de Vigilância Sanitária - ANVISA - cuja finalidade institucional "é promover a proteção da saúde da população por intermédio do controle sanitário da produção e da comercialização de produtos e serviços submetidos à vigilância sanitária, inclusive dos ambientes, dos processos, dos insumos e das tecnologias a eles relacionados”. 
Além disso, a Agência exerce o controle de portos, aeroportos e fronteiras e a interlocução junto ao Ministério das Relações Exteriores e instituições estrangeiras para tratar de assuntos internacionais na área de vigilância sanitária (BELIK, 2003). Porém suas resoluções e normas, em sua maioria, são direcionadas apenas a cozinhas comerciais e industriais, ignorando os cuidados básicos que devem ser tomados pelas donas de casa e/ ou pessoas responsáveis por fazer a refeição diária consumida nos milhares de lares brasileiros durante a produção, armazenamento e seleção de matéria-prima.

Tendo em vista esta lacuna, o objetivo deste trabalho foi identificar falhas higiênico sanitárias no processo de produção de refeições domésticas utilizando o instrumento fornecido pela ANVISA na RDC 275, uma vez que a importância no controle de boas práticas de manipulação não é divulgada de forma a atingir toda a população o que compromete a percepção dos riscos de contaminação em cozinhas domiciliares.

\section{Boas Práticas de Fabricação de Alimentos}

Em 15 de setembro de 2004, a Agência Nacional de Vigilância Sanitária publicou a resolução RDC nº 216 que considera, em sua essência, a proteção à saúde da população através da determinação, inspeção e melhoria das ações de controle higiênico-sanitário na área de alimentos (ANVISA, 2004).

A referida resolução tem como objetivo "estabelecer procedimentos de Boas Práticas para Unidades de Alimentação a fim de garantir as condições higiênico - sanitárias do alimento preparado” (ANVISA, 2004).

Cabe destacar que a RDC $N^{\circ} 216$ se aplica a todos os estabelecimentos que realizam uma ou mais das seguintes atividades: manipulação, preparação, fracionamento, armazenamento, distribuição, transporte, exposição à venda e entrega de alimentos. Também estão obrigados a obedecer a regulamentos específicos as comissarias instaladas em portos, aeroportos, fronteiras e terminais alfandegários.

O controle de qualidade nas Unidades de Alimentação é importante e abrangente, isto é, engloba diversos pontos na preparação dos alimentos, desde as situações básicas, como 
técnicas de preparo que definem as necessidades culinárias, até técnicas e instruções que garantem a segurança dos alimentos.

A resolução citada acima estabelece os pontos aos quais os estabelecimentos devem estar atentos. Estes por sua vez, devem ser constantemente analisados a fim de evitar qualquer tipo de contaminação que pode provir de qualquer uma das macro áreas contempladas nesta resolução. São elas: condições das edificações, instalações, equipamentos, utensílios e móveis; higienização das instalações, equipamentos, móveis e utensílios; controle integrado de vetores e pragas urbanas; abastecimento de água; manejo dos resíduos; manipuladores; matérias-primas, ingredientes e embalagens e preparação do alimento.

Como um instrumento auxiliar da RDC 216, a RDC $\mathrm{N}^{\circ} 275$, de outubro de 2002, foi publicada com o intuito de aprovar o Regulamento Técnico de Procedimentos Operacionais Padronizados (POP) aplicados aos Estabelecimentos Produtores/Industrializadores de Alimentos e a Lista de Verificação das Boas Práticas de Fabricação em Estabelecimentos Produtores/Industrializadores de Alimentos (ANVISA, 2002,). A RDC n 275 também estabelece os requisitos necessários para a elaboração dos POP's, os quais devem ser desenvolvidos para a higienização das instalações, equipamentos, móveis e utensílios; higiene e saúde dos manipuladores; manejo de resíduos; manutenção preventiva e calibração de equipamentos; controle integrado de vetores e pragas urbanas; seleção das matérias-primas, ingredientes e embalagens; e programa de recolhimento de alimentos.

De acordo com as recomendações, para cada um dos procedimentos acima, baseados no Manual de Boas Práticas de Fabricação, deve ser feita uma análise seguida de aprovação e assinatura pelo responsável técnico, responsável pela operação e responsável legal, para que seja firmado o compromisso de aplicação, monitoramento, avaliação, registro e manutenção dos mesmos (ANVISA, 2002). Portanto, os POP's requerem um comprometimento das pessoas envolvidas em diversos níveis de participação.

Nessa mesma direção ressalta-se que é extremamente importante que exista um programa de capacitação dos funcionários e que sejam disponibilizados os equipamentos necessários para a realização das operações, que devem estar especificados nos POP’s, assim como os de proteção individual (EPI). Devem estar facilmente acessíveis para os responsáveis pela realização das operações e às autoridades sanitárias, anexados ao Manual de Boas Práticas de Fabricação (ANVISA, 2002).

Embora muito eficientes em cozinhas comerciais, tais legislações não possuem diretrizes voltadas à realidade domiciliar, ou seja, não há regulamento específico ou qualquer tipo de campanha publicitária ou material educativo que elucide donas de casa e seus 
funcionários sobre a delicada e minuciosa tarefa de reduzir riscos de contaminação e, consequentemente, poupar suas famílias de desenvolver doenças relacionadas a má alimentação além da redução do desperdício.

Para que esta prevenção aconteça de forma correta é necessário que além da aplicação das boas práticas, os riscos de cada processo sejam identificados a fim de priorizar o momento exato de intervir visando prevenir a contaminação. Desta forma além dos POPs é necessário também o controle via fluxograma por preparação. Este fluxograma é materializado na forma das Análises de Perigo e Pontos Críticos de Controle (APPCC).

\section{Análises de Perigo e Pontos Críticos de Controle - APPCC}

O APPCC foi introduzido no ramo da alimentação em 1971 na U.S. Conference on Food Protection. O interesse no assunto foi despertado por tratar-se de um sistema que garante a segurança do alimento, e em pouco tempo tornou-se tema de diversos artigos, no qual foi amplamente divulgado, revisto, adotado e sistematizado (SILVA Jr, 2007).

Atualmente o APPCC é utilizado no âmbito internacional para garantir a segurança do alimento e é aplicado em todas as etapas que representam riscos à segurança do produto, como por exemplo: na produção, transformação, transporte, distribuição, armazenamento, exposição à venda, consumo, entre outros fatores que podem representar riscos à segurança do produto. Envolve também não somente as etapas, mas também as pessoas contidas nos processos citados acima (SILVA Jr, 2007).

Na implementação e aplicação do APPCC é fundamental o cumprimento dos princípios e regras das Boas Práticas. A ausência das mesmas inviabiliza a execução do APPCC, pois não há condições do mesmo acontecer sozinho (SILVA Jr, 2007).

Tendo como base a intensa relação entre as Boas Práticas e o APPCC, toda a equipe, desde os chefes até manipuladores, deve estar inteiramente engajada para que a implementação do sistema seja a mais coesa possível, isto é, que as exigências das Boas Práticas nos estabelecimentos sejam cumpridas (RIBEIRO - FURTINI et al., 2006).

Como princípio, o APPCC consiste em realizar uma análise de perigos, determinar os pontos críticos de controle (PCC), estabelecer os limites críticos, estabelecer um sistema de vigilância de controle dos PCC’s, estabelecer as medidas corretivas quando um PCC não está controlado, implantar um sistema de procedimentos que comprovem a eficácia do sistema e 
desenvolver um sistema de documentação de todos os procedimentos e registros (RIBEIRO FURTINI et al., 2006).

A partir da observância destes princípios básicos do APPCC, a sua aplicação é definida a partir de algumas seqüências de tarefas descritas nos parágrafos abaixo (SILVA Jr, 2007).

Inicialmente é formada uma equipe especializada APPCC a fim de formular um plano eficaz. Esta, por sua vez, pode ser própria ou contratada. Em seguida o produto é descrito de forma completa, isto é, contém informações desde composição química até inocuidade do produto, além da finalidade de uso e consumidores finais/usuários (RIBEIRO - FURTINI et al., 2006).

Outros fatores também são observados, como um fluxograma com todas as fases de operações do produto, confirmação “in loco” do mesmo, compilação de uma lista de perigos relacionados em cada fase, realização de uma análise dos perigos e exame das medidas para controlar os perigos identificados (RIBEIRO - FURTINI et al., 2006).

Por meio dos itens anteriores, são definidos os PCC’s, que por sua vez devem ser acompanhados de limites individuais, sistema de vigilância, medidas corretivas, procedimentos de comprovação e documentação comprobatória (RIBEIRO - FURTINI et al., 2006).

A grande vantagem do APPCC é que o mesmo é um sistema multidisciplinar, ou seja, pode ser adequado em diversas áreas distintas. Outra característica a se frisar é a constante evolução do mesmo com a aplicação, o que o torna um sistema robusto. Por fim, temos o APPCC como uma metodologia que garante a segurança do produto final, que no caso desta obra, garante a segurança do alimento, isto é, certifica o usuário ou consumidor final que o produto consumido é de qualidade e está dentro dos padrões estipulados pelos órgãos reguladores (SILVA Jr, 2007).

Assim sendo, este trabalho foi desenvolvido a fim de investigar se os paradigmas que norteiam a produção de refeições se adequam às unidades domésticas (SILVA Jr, 2007).

Para tanto serão apresentados no próximo item o desenho e ferramentas de estudo, a amostra, o tratamento e a análise dos dados. 


\section{METODOLOGIA}

Trata-se de um estudo de caso exploratório que se caracteriza pelo estudo profundo e exaustivo de um ou de poucos objetos de maneira que permita seu amplo e detalhado conhecimento.

Este trabalho consistiu na observação das condições de processamento de alimentos em ambiente domiciliar para proporcionar maiores informações sobre o assunto que se vai investigar e facilitar a delimitação do tema ou descobrir um novo tipo de enfoque para o assunto. A pesquisa foi classificada como qualitativa, uma vez que os dados foram coletados por meio de interação social e analisados subjetivamente (AKUTSU; COELHO, 2008).

Foram inspecionadas 9 (nove) residências da cidade de Brasília/DF, sendo 3 (três) da classe econômica A, 3 (três) da B e 3 (três) da C (ABEP, 2008), entre dezembro de 2008 e fevereiro do ano 2009. As visitas tiveram duração aproximada de 4 (quatro) horas e foram realizadas em 9 (nove) dias diferentes, preferencialmente aos finais de semana.

A função do Critério de Classificação Econômica Brasil (CCEB), é estimar o poder de compra das pessoas e famílias urbanas, abandonando a pretensão de classificar a população em termos de classes sociais. A divisão de mercado definida abaixo é exclusivamente de classes econômicas (ABEP, 2008).

Segundo a ABEP (2008), a classe econômica A é subdividida em A1 e A2, sendo que a classe A1 é composta por famílias com poder aquisitivo entre $\mathrm{R} \$ 6.564,00$ a $\mathrm{R} \$ 9.732,00$ e a A2 por famílias com poder aquisitivo igual ou maior a $\mathrm{R} \$ 9.733,00$; a classe $\mathrm{B}$, também subdividida em B1, igual ou maior a $\mathrm{R} \$ 3.479,00$, e $\mathrm{B} 2$ entre $\mathrm{R} \$ 2.013,00$ e $\mathrm{R} \$$ 3.478,00; classe C, composta por C1, com poder aquisitivo igual ou superior a R \$1.195,00, e C2, com renda entre $R$ \$ 726,00 e $R$ \$ 1.194,00; já a classe $D$ tem poder aquisitivo que varia entre $R$ \$ 485,00 e R \$ 725,00; e, por fim, a classe econômica E, com poder aquisitivo entre R \$ 277,00 e $\mathrm{R} \$ 484,00$. A escolha dessa classificação se deveu ao impacto dos recursos financeiros sobre a aquisição de conhecimentos e infra-estrutura domiciliar.

Os domicílios visitados foram selecionados por conveniência. Dentre os que se disponibilizaram a ser objetos desta pesquisa os pertencentes às classes D e E foram excluídas devido impossibilidade de encontrar responsáveis pelo domicílio dispostos serem inspecionados. Por fim, todos lares visitados estão localizados no Distrito Federal e todos os 
responsáveis pelos domicílios assinaram o termo de consentimento livre e esclarecido (Apêndice 1).

A ferramenta utilizada para análise da exposição a contaminação domiciliar foi o check list da RDC 275 de 21 de outubro de 2002, que “estabelece Procedimentos Operacionais Padronizados que contribuam para a garantia das condições higiênico-sanitárias necessárias ao processamento/industrialização de alimentos, complementando as Boas Práticas de Fabricação" (VISALEGIS, 2002, pg 126).

O check list fornecido na RDC $n^{\circ}$ 275/2002 é composto por 5 (cinco) macro itens. Estes, por sua vez, são subdivididos em itens e micro itens contemplando todos os quesitos necessários para garantir a segurança dos alimentos. Os macro itens estipulados na legislação citada são: 1. Edificações e Instalações; 2. Equipamentos, Móveis e Utensílios; 3. Manipuladores; 4. Produção e Transportes dos Alimentos; e 5. Documentação.

Porém como o presente estudo tem como objetivo contemplar itens relevantes as cozinhas domiciliares, apenas os primeiros quatro macro itens acima relacionados foram utilizados como instrumentos deste estudo.

Cada macro analisado foi classificado da seguinte forma:

- Atende Totalmente: quando todos os micro itens do formulário obtiveram resposta “sim” atribuída;

- Atende Parcialmente: quando no mínimo um dos micro itens obtiveram resposta "sim” atribuída;

- Não Atende: quando todos os micro itens do formulário obtiveram resposta "não" atribuída.

Na seqüência da compilação dos dados, os mesmos foram analisados por meio de participação percentual e média aritmética, tendo em vista que as opções "Atende Totalmente”, “Atende Parcialmente” e "Não Atende”.

Após a compilação e análise dos dados, os resultados encontrados foram classificados como Grupo 1 (G1) com 76 a 100\% de atendimento, Grupo 2 (G2) com 51 a 75\% de atendimento e Grupo 3 (G3) com 0 a 50\% dos itens atendidos, de acordo com a classificação disponibilizada no instrumento utilizado. 


\section{RESULTADOS E DISCUSSÃO}

Com base na segmentação acima determinada pelo Critério de Classificação Econômica Brasil da ABEP, 2008, foram selecionadas 9 (nove) famílias denominadas de acordo com a ordem de visitação, como segue: Família 1, Família 2, Família 3, Família 4, Família 5, Família 6, Família 7, Família 8 e Família 9. Sendo as famílias 1, 5 e 6 pertencentes a classe social A, as famílias 3, 4 e 9 pertencentes a classe social B e, por fim, as famílias 2, 7 e 8 pertencentes a classe social $\mathrm{C}$.

Analisando a distribuição percentual da adequação a RDC 275/2002, em todos os domicílios visitados, sem subdividi-los de acordo com a classe econômica a que pertencem, as nove famílias foram classificadas como G3, pois, em geral, atenderam a 38\% das exigências da legislação, ou seja, apresentam grande predisposição para que a contaminação alimentar ou suas conseqüências aconteçam.

Os maiores perigos de contaminação encontrados nas residências visitadas são relacionados a presença de animais domésticos na área de produção, utilização de utensílios de madeira e inadequada higiene pessoal e ambiental. Dentre as não conformidades destaca se ainda a falta de higiene das mãos e uniformização inadequada, uma vez que principalmente as donas de casa pertencentes à classe econômica As donas de casa mantém contato com seus animais de estimação enquanto manipulam alimentos e não higienizam suas mãos adequadamente durante o processo ou trocam de roupa para tanto, aumentando o risco do desenvolvimento de zoonoses, como a toxoplasmose, por exemplo.

Bryan (1995), em seu estudo sobre análise da operação de produção de alimentos, relata que os uniformes devem ser de cores claras e não apresentar sujidades, sendo obrigatório o uso de toucas cobrindo todo o cabelo e os sapatos devem ser fechados, o uso de esmaltes, batons e adereços não deve ser permitido. Além disso, demonstra os perigos do uso de adereços, pois caracterizam meio para acúmulo de bactérias e posterior contaminação dos alimentos, tendo ainda o risco de caírem acidentalmente em preparações. O que reforça a necessidade de esclarecimento das donas de casa para os procedimentos corretos no manuseio de alimentos.

As donas de casa pertencentes à classe C não demonstraram contato com animais de estimação, porém manipulam e fazem a higiene ambiental ao mesmo tempo, também sem

higienizar as mãos de forma adequada o que expõe o alimento ao perigo químico. Além de 
possuírem utensílios e equipamentos muito antigos e com condição de higiene e manutenção precárias. Isto demonstra que tais manipuladores demonstram não ter conhecimento de todos os tipos de perigo aos quais os alimentos podem ser expostos, são eles físicos químicos e biológicos.

Em todas as classes sociais o uso de adereços, esmaltes e sapatos abertos é predominante, sendo menos evidente quando o manipulador era empregada doméstica e não a dona de casa. Secretárias do lar apresentam também maior preocupação com a condição do cabelo (mantendo-os presos a maior parte do tempo) e higienização ambiental. Em contra partida estas preocupam-se menos com condições de edificação e com atos que causam a contaminação cruzada, como utilizar a mesma faca para contar carne crua e assada sem antes higienizar a faca de forma adequada. Os manipuladores demonstraram não também possuir conhecimentos quanto o controle de temperatura que deve ser aplicado nas mais diversas fases da manipulação dos alimentos.

Observou-se também que os manipuladores do sexo masculino demonstram graves falhas de manipulação, pois tendem a levar a mão às diferentes partes do corpo por mais vezes que as manipuladoras do sexo feminino, especialmente devido à sudorese elevada, além de apresentarem o hábito de provar a comida com as mãos e consumirem comidas em cocção incompleta.

Segundo Sounis, 1996, os funcionários devem lavar as mãos antes de iniciarem o trabalho ou após usarem o banheiro, tossir, espirrar, coçar-se, assoar o nariz ou tocar ferimentos e curativos, e, o estabelecimento deve ser provido de pia, sabonete, papel toalha e água quente para facilitar a higiene pessoal que deve ser rigorosa. De forma global, nas poucas vezes em que lavavam as mãos, os manipuladores não utilizavam sabonete bactericida inodoro para higienizar as mãos, fazendo uso de detergentes neutros ou sabão em barra potencialmente incapazes de eliminar muitos dos microrganismos que podem ser transmitidos pelas mãos do homem.

Analisando a Tabela 1, na qual as classes econômicas são separadas, apesar de ambas as classes econômicas B e C terem sido classificadas como G3, a classe C apresenta menor percentual de atendimento aos itens imprescindíveis e, consequentemente, maior risco de desenvolver alguma doença transmitida por alimento (DTA). 
TABELA 1 - Percentual de adequação dos macro itens da RDC 275/2002 em domicílios do Distrito Federal -2009.

\begin{tabular}{l|ccc}
\hline \multirow{2}{*}{ \% Adequação } & \multicolumn{3}{|c}{ Classificação (\%) } \\
\cline { 2 - 4 } & Classe A & Classe B & Classe C \\
\hline \% Atende Totalmente & $60 \%$ & $40 \%$ & $14 \%$ \\
\% Atende Parcialmente & $36 \%$ & $43 \%$ & $32 \%$ \\
\% Não Atende & $4 \%$ & $17 \%$ & $54 \%$ \\
Classificação por Grupos & $\mathbf{G 2}$ & $\mathbf{G 3}$ & $\mathbf{G 3}$ \\
\hline
\end{tabular}

Já a Tabela 2 mostra que a classificação da classe econômica A como G2 decorre do fato desta possuir condições de edificação e instalação melhores que as demais classes, além de equipamentos e utensílios modernos em conseqüência do maior poder aquisitivo. No entanto em se tratando de Produção e Transporte de Alimentos, macro item que aborda seleção de matéria prima, análise de rótulos e acondicionamento adequado do alimento, a classe A é classificada como G3 a semelhança das demais, o que comprova que conhecimentos específicos sobre tratamento de alimentos e matérias-primas não são de conhecimento da população estudada.

A classe econômica C em comparação as outras classes econômicas dispõe de menos capital para cumprir com todos seus compromissos mensais, tem menos acesso a informações e educação, e tem acesso restrito a saúde o que explica o fato desta apresentar os piores resultados, uma vez que não há como adequar-se sem ter acesso à informação correta e não há como abrir mão de pagar contas básicas para investir em adequação de instalações (BARROS, 1995). 
Tabela 2 - Análise vertical dos resultados obtidos a partir da aplicação check list da RDC 275/2002 em nove residências do DF, no período de dezembro de 2008 a fevereiro de 2009.

\begin{tabular}{l|c|c|c}
\hline \multirow{2}{*}{ \% Adequação por macro itens } & \multicolumn{3}{c}{ Classes Econômicas } \\
\cline { 2 - 4 } & A & B & C \\
\hline 1. EDIFICAÇÃO E INSTALAÇÕES & $\mathrm{G} 2$ & $\mathrm{G} 3$ & $\mathrm{G} 3$ \\
2. EQUIPAMENTOS, MÓVEIS E UTENSÍLIOS & $\mathrm{G} 2$ & $\mathrm{G} 3$ & $\mathrm{G} 3$ \\
3. MANIPULADORES & $\mathrm{G} 2$ & $\mathrm{G} 3$ & $\mathrm{G} 3$ \\
4. PRODUÇÃO E TRANSPORTE DO ALIMENTO & $\mathrm{G} 3$ & $\mathrm{G} 3$ & $\mathrm{G} 3$ \\
Classificação Final & $\mathrm{G} 2$ & $\mathrm{G} 3$ & $\mathrm{G3}$ \\
\hline
\end{tabular}

Embora de uma forma geral a classe A tenha sido classificada com G2 para o macro item Manipuladores, analisando especificamente o micro item estado de saúde dos manipuladores, todas as classes econômicas foram classificadas como G3, ou seja, nenhuma toma o devido cuidado com a saúde do manipulador.deixando de lado cuidados importantes como observar presença de feridas ou machucados ou facilitar para que estes realizem exames de sangue, fezes e urina anualmente.Tal levantamento é de extrema importância uma vez que como mencionado acima, o manipulador é um dos principais focos de contaminação dos alimentos devido maus hábitos higiênicos (FDA, 2002). Uma das medidas cabíveis para minimizar perigo de contaminação é realizar alguns cuidados para prevenção, detecção e cura de algumas doenças endêmicas, crônicas ou agudas, que possam prejudicar o indivíduo e comprometer a qualidade do alimento.

Das três classes econômicas avaliadas, a classe B foi a que obteve uma diferenciação importante. Uma das três casas visitadas pertencia a uma nutricionista, ou seja, profissional especializada em boas práticas de manipulação e, consequentemente, das nove residências visitadas foi a única classificada individualmente como G1, ou seja, atende a mais de $76 \%$ dos itens imprescindíveis. Tal classificação favoreceu a classificação geral da classe econômica B, uma vez que apenas três residências pertencentes a esta classe social faziam parte da amostra. Neste domicílio em especial os maiores problemas encontrados foram relacionados aos macro itens Edificação e Instalações e Equipamentos e Móveis e Utensílios. A dimensão da área física não é condizente com as necessidades de fluxo de produção, pois é uma área pequena o que limita a quantidade de móvel a ser disponibilizado para manipulação. Não entendi 
Por fim, comparando os resultados demonstrados na Tabela 2 com os resultados demonstrados no estudo de Akutsu et. al. (2005), que classificou 50 (cinqüenta) estabelecimentos produtores de alimentos, da região de Brasília, Distrito Federal, de acordo com o cumprimento dos itens imprescindíveis do formulário publicado pela Agência Nacional de Vigilância Sanitária, a fim de avaliar as boas práticas da fabricação de alimentos, para o macro item Equipamentos, Móveis e Utensílios Observa-se que os domicílios comportam-se da mesma forma que os restaurantes comerciais estudados no estudo citado acima, demonstrando que a falta de conhecimento relativo à escolha de equipamentos adequados ao volume de produção, bem como a manutenção dos mesmos depende de conhecimentos específicos de boas práticas de manipulação aos quais a amostra em questão demonstrou não possuir acesso. 


\section{CONCLUSÕES}

Com base nos resultados apresentados e na realidade observada dentro das residências visitadas, conclui-se que os riscos de contaminação alimentar dentro de cozinhas domiciliares são relevantes e aumentam de maneira inversamente proporcional ao poder aquisitivo da família analisada.

Desta forma, cursos sobre Boas Práticas de Manipulação deveriam ser mais difundidos a toda população, uma vez que para aqueles que as desconhecem é difícil identificar quais aspectos de suas áreas de produção e comportamentos seus manipuladores apresentam que podem ou não causar riscos a saúde das famílias.

Inadequações com Edificação e Instalações foram demonstradas em todas as classes econômicas, diante deste fato sugere-se que arquitetos, engenheiros e mestres de obras recebam tomem conhecimento das exigências da ANVISA de forma que possam cumprir as determinações reduzindo perigos de contaminação derivados do fluxo de produção inadequado.

Não só escritórios de arquitetura e empreiteiros deveriam preocupar-se em divulgar conhecimentos nesta área, os Sindicato das Empregas Domésticas, Sindicato de Bares e Restaurantes, Sindicato de Hospitais, Casa de Saúde e Clínicas, o próprio Conselho Regional de Nutrição, as Instituições que formam profissionais de Nutrição, dentre outros, devem unirse a fim de desenvolver programas de capacitação de manipuladores juntamente com a ANVISA de forma que as famílias ficassem menos expostas aos perigos de contaminação do alimento.

À ANVISA cabe também a responsabilidade de elaborar campanhas educativas que sejam divulgadas em mídia eletrônica (televisão e rádio) e mídia impressão (jornal, revistas, frontlight, dentre outros) de forma a atingir a população que não possa comparecer aos cursos de capacitação. Além da importância de elaborar um check - list específico para domicílios de forma que facilite o controle domiciliar.

O principal limitante dos resultados deste estudo foi o número reduzido de domicílios avaliados e principalmente a dificuldade de conseguir a autorização para visitá-los. A principal sugestão é que novos estudos, mais específicos, sejam realizados em domicílios de 
forma a elucidar as donas de casa quanto à importância de capacitar seus funcionários e a si próprias quanto às boas práticas de fabricação.

Por fim, os resultados apresentados não podem ser utilizados para generalizar toda a população ou classes econômicas, devido ao pequeno universo analisado. Entretanto deve servir como um alerta, tanto aos profissionais da área de segurança do alimento quanto aos chefes de famílias e donas de casa sobre riscos de contaminação alimentar aos quais estão expostas suas famílias. 


\section{REFERÊNCIAS BIBLIOGRÁFICAS}

1. ABEP. Critério de Classificação Econômica Brasil 2008. Disponível em: < http://www.abep.org/codigosguias/Criterio_Brasil_2008.pdf>. Acesso em: 15 fev. 2009.

2. AKUTSU, Rita de Cássia; BOTELHO, Raquel A.; CAMARGO, Erika B.; SAVIO, Karin Eleonora O.; ARAÙJO, Wilma C. Adequação das boas práticas de fabricação em serviços de alimentação. Rev. Nutr. , Campinas, v. 18, n. 3, jun. 2005.

3. AKUTSU, R. C. ; COELHO, M. Metodologia Científica: planejamento e técnicas. Apostila. Brasília, 2008. 46p. ANVISA - Agência Nacional de Vigilância Sanitária. Instituicional.

4. ALMEIDA, Rogéria C. C.; KUAYE, Arnaldo Y.; SERRANO, Paulo Fernando A. Avaliação e controle da qualidade microbiológica de mãos de manipuladores de alimentos. Rev. Saúde Pública, 29 (4), p. 290-95, 1995.

5. ANVISA - Agência Nacional de Vigilância Sanitária. RDC n²16, de 15 de setembro de 2004.

6. ANVISA - Agência Nacional de Vigilância Sanitária. RDC $n^{\circ} 275$, de 21 de outubro de 2002.

7. BALSANELLI, A.P.; JERICO, M.C. Os reflexos da gestão pela qualidade total em instituições hospitalares brasileiras. Acta paul. enferm., São Paulo, v. 18, n. 4, 2005. Acesso em: 052008.

8. BARROS, Ricardo P; MENDONÇA, Rosane S.P. Os Determinantes da Desigualdade no Brasil. Rio de Janeiro, 1995.

9. BELIK, Walter. Perspectivas para segurança do alimento e nutricional no Brasil. Saúde Soc., São Paulo, v. 12, n. 1, jun. 2003

10. BRYAN, F. I. Hazard analysis of food service operations. p. 78, 1981. 
11. HYRAYAMA, Karin B. ; MAISTRO, Liliane C. ; MARTINELLI, Rita Mª Controle de Qualidade Higiênico-Sanitária no Processo de Produção de Alimentos através da detecção de Staphylacoccus aureus em Mãos de Manipuladores. Revista Nutrição em Pauta. Ed. Novembro/ Dezembro, 2005

\section{LONGO, Rose M.J. Gestão de Qualidade: Evolução Histórica, Conceitos Básicos e} Aplicação na Educação. - IPEA, 1996.

13. MESQUITA, Marizete O.; DANIEL, Ana P.; SACCOL, Ana L. de F.; MILANI, Liana I. G.; FRIES, Leadir L. M. Qualidade Microbiológica no Processamento do Frango Assado em Unidade de Alimentação e Nutrição. Ciênc. Tecnol. Aliment., Campinas, 26(1): 198-203, jan.-mar. 2006

14. RIBEIRO-FURTINI, Larissa Lagoa; ABREU, Luiz Ronaldo de. Utilização de APPCC na indústria de alimentos. Ciênc. agrotec., Lavras, v. 30, n. 2, abr. 2006.

15. SANSANA, Cellem D.; BORTOLOZO, Eliana Q. Segurança do alimento Domiciliar: Conservação da Carne Mediante a Aplicação do Frio. Universidade tecnológica Federal do Paraná v.02, n. 39, 2008.

16. SILVA Jr, Eneo Alves Manual de Controle Higiênico-Sanitário em Serviços de Alimentação. 6a edição. Ed. Livraria Varela, São Paulo, 2007.

17. SOUNIS, E. Manual de Higiene e Medicina do Trabalho, 3 ed, São Paulo, Mc Gram Hill, 1995, p. 166.

18. ZANDONADI, Renata Puppin; BOTELHO, Raquel B. A.; SÁVIO, Karin E. O.; AKUSTU, Rita de Cássia; ARAÚJO, Wilma $\mathrm{M}^{\mathrm{a}} \mathrm{C}$. . Atitudes de risco do consumidor em restaurantes de auto-serviço. Rev. Nutr., Campinas, v. 20, n. 1, fev. 2007. 


\section{ANEXO I - TERMO DE CONSENTIMENTO}

Universidade de Brasília - UnB

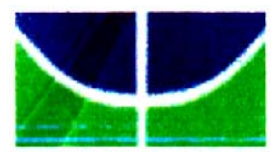

Centro de Excelência em Turismo - CET

Pós-Graduação Lato Sensu - Qualidade em Alimentos

Projeto: Convivendo com o Inimigo - Cozinha Domiciliar e Riscos de Contaminação Alimentar

Orientador: Prof ${ }^{\mathrm{a}}$. Dr. ${ }^{\mathrm{a}}$ Rita de Cássia Akutsu

Orientanda: Rafaela Nemer

\section{Brasília, DIA de MÊS de 2009}

\section{TERMO DE CONSENTIMENTO}

\section{Da: Universidade de Brasília}

\section{A/C: NOME DO RESPONSÁVEL PELO DOMICÍLIO}

O Centro de Excelência em Turismo da Universidade de Brasília solicita a autorização de Vossa Senhoria para realizar a pesquisa intitulada "Convivendo com o Inimigo - Cozinha Domiciliar e Riscos de Contaminação Alimentar” em sua residência. Esse projeto é de grande importância para o conhecimento da segurança de alimentos. Os resultados obtidos serão de maior relevância para atividades futuras de planejamento de refeições de forma a evitar a produção de alimentos inseguros para sua e demais famílias brasileiras e a ocorrência de doenças causadas por alimentos contaminados.

A amostra da pesquisa engloba nove domicílios do Distrito Federal os quais serão divididos igualmente entre três classes econômicas diferentes, ou seja, serão visitadas três casas da classe econômica A, B e C.

Para esta pesquisa serão coletados dados referentes a edificação e instalações; equipamentos, móveis e utensílios; manipuladores; e produção e transporte dos alimentos. Todos os dados serão coletados na própria unidade pelo pesquisador da $\mathrm{UnB}$, devidamente treinado e preparado para tal atividade.

As residências interessadas em participar da pesquisa terão obrigatoriamente que assinar um termo de consentimento autorizando a coleta de dados, que inclui, por parte dos 
pesquisadores, a garantia de sigilo da identidade do proprietário / responsável participante quanto aos resultados obtidos.

Para que esses objetivos sejam atingidos, e seu lar possa compor a amostra da pesquisa, é necessário o consentimento de Vossa Senhoria.

Desde já agradecemos a sua atenção e lembramos que a participação da sua residência contribuirá para o conhecimento de dados sobre a segurança de alimentos, que ainda não se tem acesso na bibliografia brasileira.

Para maiores esclarecimentos favor entrar em contato com a Pesquisadora, Rafaela Nemer, no celular (61) 8405-5521.

\section{Atenciosamente,}

Rafaela Nemer

Pesquisadora

Dr ${ }^{a}$ Rita de Cássia Akutsu

Coordenadora do projeto

NOME DO RESPONSÁVEL

PELA RESIDÊNCIA 


\section{ANEXO II - CHECK - LIST (ANVISA)}

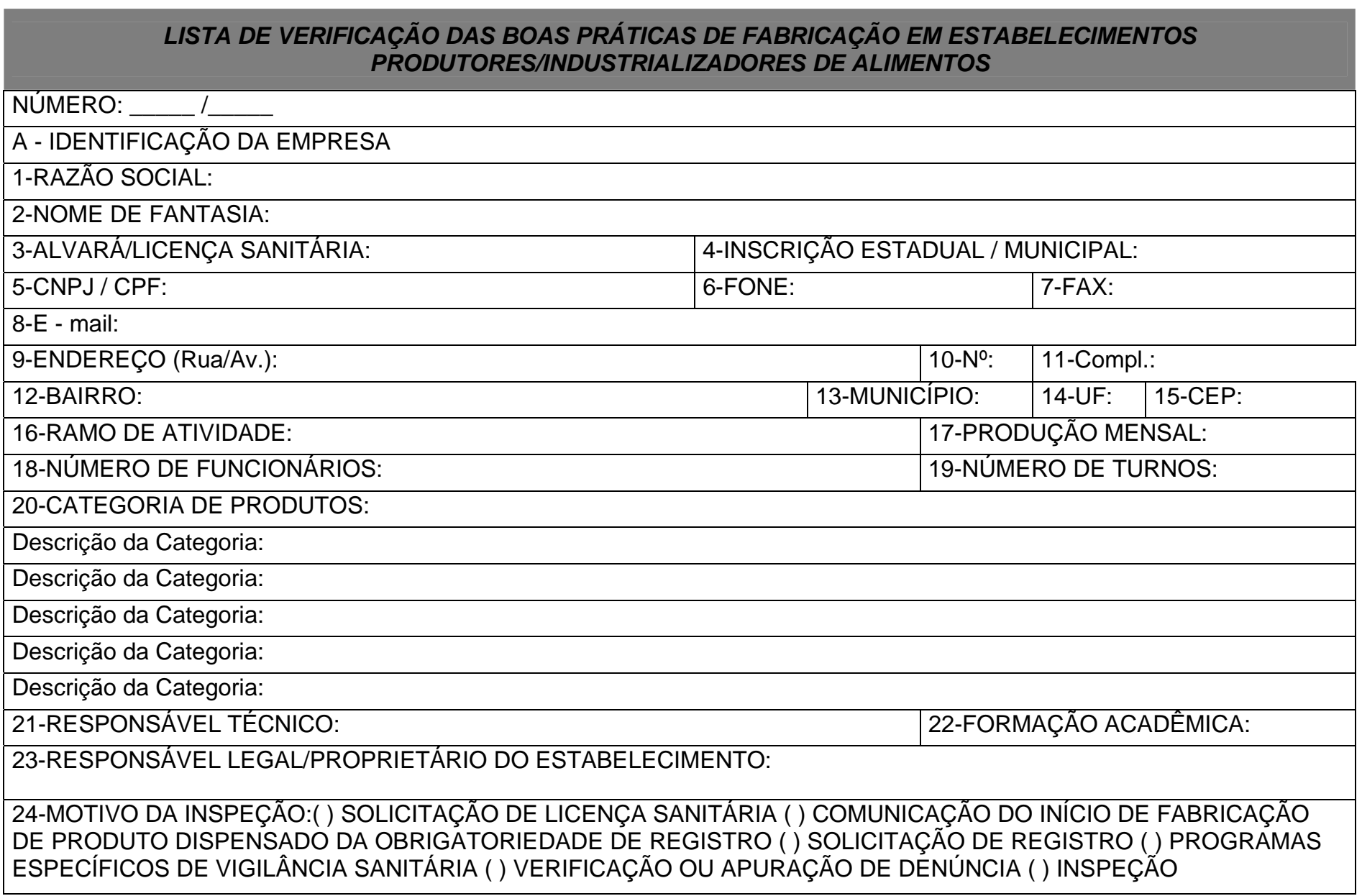




\begin{tabular}{|c|c|c|c|}
\hline B - AVALIAÇÃO & SIM & NÃO & NA(*) \\
\hline \multicolumn{4}{|l|}{ 1. EDIFICAÇÃO E INSTALAÇÕES } \\
\hline \multicolumn{4}{|l|}{ 1.1 ÁREA EXTERNA: } \\
\hline \multicolumn{4}{|l|}{$\begin{array}{l}\text { 1.1.1 Área externa livre de focos de insalubridade, de objetos em desuso ou estranhos ao ambiente, de } \\
\text { vetores e outros animais no pátio e vizinhança; de focos de poeira; de acúmulo de lixo nas imediações, de } \\
\text { água estagnada, dentre outros. }\end{array}$} \\
\hline \multicolumn{4}{|l|}{ 1.2 ACESSO: } \\
\hline \multicolumn{4}{|l|}{ 1.2.1 Direto, não comum a outros usos ( habitação). } \\
\hline \multicolumn{4}{|l|}{ 1.3 ÁREA INTERNA: } \\
\hline \multicolumn{4}{|l|}{ 1.4.2 Em adequado estado de conservação (livre de defeitos, rachaduras, trincas, buracos e outros). } \\
\hline \multicolumn{4}{|l|}{$\begin{array}{l}\text { 1.4.3 Sistema de drenagem dimensionado adequadamente, sem acúmulo de resíduos. Drenos, ralos } \\
\text { sifonados e grelhas colocados em locais adequados de forma a facilitar o escoamento e proteger contra a } \\
\text { entrada de baratas, roedores etc. }\end{array}$} \\
\hline \multicolumn{4}{|l|}{1.5 TETOS: } \\
\hline \multicolumn{4}{|l|}{ 1.5.1 Acabamento liso, em cor clara, impermeável, de fácil limpeza e, quando for o caso, desinfecção. } \\
\hline \multicolumn{4}{|l|}{$\begin{array}{l}\text { 1.5.2 Em adequado estado de conservação (livre de trincas, rachaduras, umidade, bolor, } \\
\text { descascamentos e outros). }\end{array}$} \\
\hline \multicolumn{4}{|l|}{ 1.6 PAREDES E DIVISÓRIAS: } \\
\hline
\end{tabular}


1.6.2 Em adequado estado de conservação (livres de falhas, rachaduras, umidade, descascamento e outros).

1.6.3 Existência de ângulos abaulados entre as paredes e o piso e entre as paredes e o teto.

1.7 PORTAS:

1.7.1 Com superfície lisa, de fácil higienização, ajustadas aos batentes, sem falhas de revestimento.

1.7.2 Portas externas com fechamento automático (mola, sistema eletrônico ou outro) e com barreiras adequadas para impedir entrada de vetores e outros animais (telas milimétricas ou outro sistema).

1.7.3 Em adequado estado de conservação (livres de falhas, rachaduras, umidade, descascamento e outros).

1.8 JANELAS E OUTRAS ABERTURAS:

1.8.1 Com superfície lisa, de fácil higienização, ajustadas aos batentes, sem falhas de revestimento.

1.8.2 Existência de proteção contra insetos e roedores (telas milimétricas ou outro sistema).

1.8.3 Em adequado estado de conservação (livres de falhas, rachaduras, umidade, descascamento e outros).

\section{B - AVALIAÇÃO}

1.9 ESCADAS, ELEVADORES DE SERVIÇO, MONTACARGAS E ESTRUTURAS AUXILIARES

1.9.1 Construídos, localizados e utilizados de forma a não serem fontes de contaminação.

1.9.2 De material apropriado, resistente, liso e impermeável, em adequado estado de conservação. 1.10 INSTALAÇÕES SANITÁRIAS E VESTIÁRIOS PARA OS MANIPULADORES:

1.10.1 Quando localizados isolados da área de produção, acesso realizado por passagens cobertas e calçadas.

1.10.2 Independentes para cada sexo (conforme legislação específica), identificados e de uso exclusivo para manipuladores de alimentos.

1.10.3 Instalações sanitárias com vasos sanitários; mictórios e lavatórios íntegros e em proporção adequada ao número de empregados (conforme legislação específica).

1.10.4 Instalações sanitárias servidas de água corrente, dotadas preferencialmente de torneira com acionamento automático e conectadas à rede de esgoto ou fossa séptica.

1.10.5 Ausência de comunicação direta (incluindo sistema de exaustão) com a área de trabalho e de refeições. 
1.10.6 Portas com fechamento automático (mola, sistema eletrônico ou outro).

1.10.7 Pisos e paredes adequadas e apresentando satisfatório estado de conservação.

1.10.8 lluminação e ventilação adequadas.

1.10.9 Instalações sanitárias dotadas de produtos destinados à higiene pessoal: papel higiênico, sabonete líquido inodoro anti-séptico ou sabonete líquido inodoro e anti-séptico, toalhas de papel não reciclado para as mãos ou outro sistema higiênico e seguro para secagem.

1.10.10 Presença de lixeiras com tampas e com acionamento não manual.

1.10.11 Coleta freqüente do lixo.

1.10.12 Presença de avisos com os procedimentos para lavagem das mãos.

1.10.13 Vestiários com área compatível e armários individuais para todos os manipuladores.

1.10.14 Duchas ou chuveiros em número suficiente (conforme legislação específica), com água fria ou com água quente e fria.

1.10.15 Apresentam-se organizados e em adequado estado de conservação.

1.11 INSTALAÇÕES SANITÁRIAS PARA VISITANTES E OUTROS:

1.11.1 Instaladas totalmente independentes da área de produção e higienizados.

1.12 LAVATÓRIOS NA ÁREA DE PRODUÇÃO:

1.12.1 Existência de lavatórios na área de manipulação com água corrente, dotados preferencialmente de torneira com acionamento automático, em posições adequadas em relação ao fluxo de produção e serviço, e em número suficiente de modo a atender toda a área de produção

1.12.2 Lavatórios em condições de higiene, dotados de sabonete líquido inodoro anti-séptico ou sabonete líquido inodoro e anti-séptico, toalhas de papel não reciclado ou outro sistema higiênico e seguro de secagem e coletor de papel acionados sem contato manual.

1.13 ILUMINAÇÃO E INSTALAÇÃO ELÉTRICA

1.13.1 Natural ou artificial adequada à atividade desenvolvida, sem ofuscamento, reflexos fortes, sombras e contrastes excessivos.

1.13.2 Luminárias com proteção adequada contra quebras e em adequado estado de conservação.

1.13.3 Instalações elétricas embutidas ou quando exteriores revestidas por tubulações isolantes e presas a paredes e tetos. 


\subsection{VENTILAÇ̃̃O E CLIMATIZAÇÃO:}

1.14.1 Ventilação e circulação de ar capazes de garantir o conforto térmico e o ambiente livre de fungos, gases, fumaça, pós, partículas em suspensão e condensação de vapores sem causar danos à produção.

1.14.2 Ventilação artificial por meio de equipamento(s) higienizado(s) e com manutenção adequada ao tipo de equipamento.

1.14.3 Ambientes climatizados artificialmente com filtros adequados.

1.14.4 Existência de registro periódico dos procedimentos de limpeza e manutenção dos componentes do sistema de climatização (conforme legislação específica) afixado em local visível.

1.14.5 Sistema de exaustão e ou insuflamento com troca de ar capaz de prevenir contaminações.

1.14.6 Sistema de exaustão e ou insuflamento dotados de filtros adequados.

1.14.7 Captação e direção da corrente de ar não seguem a direção da área contaminada para área limpa.

1.15 HIGIENIZAÇÃO DAS INSTALAÇÕES:

1.15.1 Existência de um responsável pela operação de higienização comprovadamente capacitado.

1.15.2 Freqüência de higienização das instalações adequada.

1.15.3 Existência de registro da higienização.

1.15.4 Produtos de higienização regularizados pelo Ministério da Saúde.

1.15.5 Disponibilidade dos produtos de higienização necessários à realização da operação.

1.15.6 A diluição dos produtos de higienização, tempo de contato e modo de uso/aplicação obedecem às instruções recomendadas pelo fabricante.

1.15.7 Produtos de higienização identificados e guardados em local adequado.

B - AVALIAÇÃO

1.15.8 Disponibilidade e adequação dos utensílios (escovas, esponjas etc.) necessários à realização da operação. Em bom estado de conservação.

1.15.9 Higienização adequada.

1.16 CONTROLE INTEGRADO DE VETORES E PRAGAS URBANAS:

1.16.1 Ausência de vetores e pragas urbanas ou qualquer evidência de sua presença como fezes, ninhos e outros. 
1.16.2 Adoção de medidas preventivas e corretivas com o objetivo de impedir a atração, o abrigo, o acesso e ou proliferação de vetores e pragas urbanas.

1.16.3 Em caso de adoção de controle químico, existência de comprovante de execução do serviço expedido por empresa especializada.

\subsection{ABASTECIMENTO DE ÁGUA:}

1.17.1 Sistema de abastecimento ligado à rede pública.

1.17.2 Sistema de captação própria, protegido, revestido e distante de fonte de contaminação

1.17.3 Reservatório de água acessível com instalação hidráulica com volume, pressão e temperatura adequados, dotado de tampas, em satisfatória condição de uso, livre de vazamentos, infiltrações e descascamentos.

1.17.4 Existência de responsável comprovadamente capacitado para a higienização do reservatório da água.

1.17.5 Apropriada freqüência de higienização do reservatório de água

1.17.6 Existência de registro da higienização do reservatório de água ou comprovante de execução de serviço em caso de terceirização.

1.17.7 Encanamento em estado satisfatório e ausência de infiltrações e interconexões, evitando conexão cruzada entre água potável e não potável.

1.17.8 Existência de planilha de registro da troca periódica do elemento filtrante.

1.17.9 Potabilidade da água atestada por meio de laudos laboratoriais, com adequada periodicidade, assinados por técnico responsável pela análise ou expedidos por empresa terceirizada.

1.17.10 Disponibilidade de reagentes e equipamentos necessários à análise da potabilidade de água realizadas no estabelecimento.

1.17.11 Controle de potabilidade realizado por técnico comprovadamente capacitado.

1.17.12 Gelo produzido com água potável, fabricado, manipulado e estocado sob condições sanitárias satisfatórias, quando destinado a entrar em contato com alimento ou superfície que entre em contato com alimento.

1.17.13 Vapor gerado a partir de água potável quando utilizado em contato com o alimento ou superfície que entre em contato com o alimento.

\footnotetext{
1.18 MANEJO DOS RESÍDUOS:
} 
1.18.1 Recipientes para coleta de resíduos no interior do estabelecimento de fácil higienização e transporte, devidamente identificados e higienizados constantemente; uso de sacos de lixo apropriados. Quando necessário, recipientes tampados com acionamento não manual.

1.18.2 Retirada freqüente dos resíduos da área de processamento, evitando focos de contaminação.

1.18.3 Existência de área adequada para estocagem dos resíduos.

1.19 ESGOTAMENTO SANITÁRIO:

1.19.1 Fossas, esgoto conectado à rede pública, caixas de gordura em adequado estado de conservação e funcionamento.

1.20 LAY-OUT:

1.20.1 Leiaute adequado ao processo produtivo: número, capacidade e distribuição das dependências de acordo com o ramo de atividade, volume de produção e expedição.

1.20.2 Áreas para recepção e depósito de matéria-prima, ingredientes e embalagens distintas das áreas de produção, armazenamento e expedição de produto final.

\section{EQUIPAMENTOS, MÓVEIS E UTENSÍLIOS}

\subsection{EQUIPAMENTOS:}

2.1.1 Equipamentos da linha de produção com desenho e número adequado ao ramo.

2.1.2 Dispostos de forma a permitir fácil acesso e higienização adequada.

2.1.3 Superfícies em contato com alimentos lisas, íntegras, impermeáveis, resistentes à corrosão, de fácil higienização e de material não contaminante.

2.1.4 Em adequado estado de conservação e funcionamento.

2.1.5 Equipamentos de conservação dos alimentos (refrigeradores, congeladores, câmaras frigoríficas e outros), bem como os destinados ao processamento térmico, com medidor de temperatura localizado em local apropriado e em adequado funcionamento.

2.1.6 Existência de planilhas de registro da temperatura, conservadas durante período adequado.

2.1.7 Existência de registros que comprovem que os equipamentos e maquinários passam por manutenção preventiva.

2.1.8 Existência de registros que comprovem a calibração dos instrumentos e equipamentos de medição ou comprovante da execução do serviço quando a calibração for realizada por empresas terceirizadas.

2.2 MÓVEIS: (mesas, bancadas, vitrines, estantes) 
2.2.1 Em número suficiente, de material apropriado, resistentes, impermeáveis; em adequado estado de conservação, com superfícies íntegras.

2.2.2 Com desenho que permita uma fácil higienização (lisos, sem rugosidades e frestas).

B - AVALIAÇÃO

2.3 UTENSÍLIOS:

2.3.1 Material não contaminante, resistentes à corrosão, de tamanho e forma que permitam fáci higienização: em adequado estado de conservação e em número suficiente e apropriado ao tipo de operação utilizada.

2.3.2 Armazenados em local apropriado, de forma organizada e protegidos contra a contaminação.

2.4 HIGIENIZAÇÃO DOS EQUIPAMENTOS E MAQUINÁRIOS, E DOS MÓVEIS E UTENSÍLIOS:

2.4.1 Existência de um responsável pela operação de higienização comprovadamente capacitado.

2.4.2 Freqüência de higienização adequada.

2.4.3 Existência de registro da higienização.

2.4.4 Produtos de higienização regularizados pelo Ministério da Saúde.

2.4.5 Disponibilidade dos produtos de higienização necessários à realização da operação.

2.4.6 Diluição dos produtos de higienização, tempo de contato e modo de uso/aplicação obedecem às instruções recomendadas pelo fabricante.

2.4.7 Produtos de higienização identificados e guardados em local adequado.

2.4.8 Disponibilidade e adequação dos utensílios necessários à realização da operação. Em bom estado de conservação.

2.4.9 Adequada higienização.

3. MANIPULADORES

3.1 VESTUÁRIO

3.1.1 Utilização de uniforme de trabalho de cor clara, adequado à atividade e exclusivo para área de produção.

3.1.2 Limpos e em adequado estado de conservação.

3.1.3 Asseio pessoal: boa apresentação, asseio corporal, mãos limpas, unhas curtas, sem esmalte, sem adornos (anéis, pulseiras, brincos, etc.); manipuladores barbeados, com os cabelos protegidos.

SIM NÃO

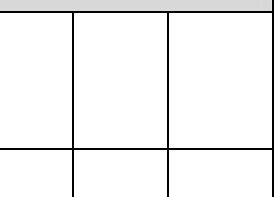

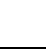

\begin{tabular}{|l|l|l|l|}
\hline & & & \\
\hline & & & \\
\hline & & & \\
\hline & & & \\
\hline & & & \\
\hline
\end{tabular}

| 


\subsection{HÁBITOS HIGIÊNICOS:}

3.2.1 Lavagem cuidadosa das mãos antes da manipulação de alimentos, principalmente após qualquer interrupção e depois do uso de sanitários.

3.2.2 Manipuladores não espirram sobre os alimentos, não cospem, não tossem, não fumam, não manipulam dinheiro ou não praticam outros atos que possam contaminar o alimento.

3.2.3 Cartazes de orientação aos manipuladores sobre a correta lavagem das mãos e demais hábitos de higiene, afixados em locais apropriados.

\subsection{ESTADO DE SAÚDE:}

3.3.1 Ausência de afecções cutâneas, feridas e supurações; ausência de sintomas e infecções respiratórias, gastrointestinais e oculares.

\subsection{PROGRAMA DE CONTROLE DE SAÚDE:}

3.4.1 Existência de supervisão periódica do estado de saúde dos manipuladores.

3.4.2 Existência de registro dos exames realizados.

3.5 EQUIPAMENTO DE PROTEÇÃO INDIVIDUAL:

3.5.1 Utilização de Equipamento de Proteção Individual. 3.6 PROGRAMA DE CAPACITAÇÃO DOS MANIPULADORES E SUPERVISÃO:

3.6.1 Existência de programa de capacitação adequado e contínuo relacionado à higiene pessoal e à manipulação dos alimentos.

3.6.2 Existência de registros dessas capacitações.

3.6.3 Existência de supervisão da higiene pessoal e manipulação dos alimentos.

3.6.4 Existência de supervisor comprovadamente capacitado.

\section{PRODUÇÃO E TRANSPORTE DO ALIMENTO}

4.1 MATÉRIA-PRIMA, INGREDIENTES E EMBALAGENS:

4.1.1 Operações de recepção da matéria-prima, ingredientes e embalagens são realizadas em local protegido e isolado da área de processamento.

4.1.2 Matérias - primas, ingredientes e embalagens inspecionados na recepção.

4.1.3 Existência de planilhas de controle na recepção (temperatura e características sensoriais, condições de transporte e outros). 
4.1.4 Matérias-primas e ingredientes aguardando liberação e aqueles aprovados estão devidamente identificados.

4.1.5 Matérias-primas, ingredientes e embalagens reprovados no controle efetuado na recepção são devolvidos imediatamente ou identificados e armazenados em local separado.

4.1.6 Rótulos da matéria-prima e ingredientes atendem à legislação.

4.1.7 Critérios estabelecidos para a seleção das matérias-primas são baseados na segurança do alimento.

4.1.8 Armazenamento em local adequado e organizado; sobre estrados distantes do piso, ou sobre paletes, bem conservados e limpos, ou sobre outro sistema aprovado, afastados das paredes e distantes do teto de forma que permita apropriada higienização, iluminação e circulação de ar.

4.1.9 Uso das matérias-primas, ingredientes e embalagens respeita a ordem de entrada dos mesmos sendo observado o prazo de validade.

4.1.10 Acondicionamento adequado das embalagens a serem utilizadas.

4.1.11 Rede de frio adequada ao volume e aos diferentes tipos de matérias-primas e ingredientes.

\section{B - AVALIAÇÃO}

\subsection{FLUXO DE PRODUÇÃO:}

4.2.1 Locais para pré - preparo ("área suja") isolados da área de preparo por barreira física ou técnica.

4.2.2 Controle da circulação e acesso do pessoal.

4.2.3 Conservação adequada de materiais destinados ao reprocessamento.

4.2.4 Ordenado, linear e sem cruzamento.

\subsection{ROTULAGEM E ARMAZENAMENTO DO PRODUTO-FINAL:}

4.3.1 Dizeres de rotulagem com identificação visível e de acordo com a legislação vigente.

4.3.2 Produto final acondicionado em embalagens adequadas e íntegras.

4.3.3 Alimentos armazenados separados por tipo ou grupo, sobre estrados distantes do piso, ou sobre paletes, bem conservados e limpos ou sobre outro sistema aprovado, afastados das paredes e distantes do teto de forma a permitir apropriada higienização, iluminação e circulação de ar.

4.3.4 Ausência de material estranho, estragado ou tóxico.

4.3.5 Armazenamento em local limpo e conservado

\begin{tabular}{|l|l|l|l|}
\hline a. & & & \\
\hline & & & \\
\hline & & & \\
\hline
\end{tabular}

\begin{tabular}{|l|l|l|l|}
\hline & & & \\
\hline & & & \\
\hline & & & \\
\hline & & & \\
\hline & & & \\
\hline
\end{tabular}


4.3.6 Controle adequado e existência de planilha de registro de temperatura, para ambientes com controle térmico.

4.3.7 Rede de frio adequada ao volume e aos diferentes tipos de alimentos.

4.3.8 Produtos avariados, com prazo de validade vencido, devolvidos ou recolhidos do mercado devidamente identificados e armazenados em local separado e de forma organizada.

4.3.9 Produtos finais aguardando resultado analítico ou em quarentena e aqueles aprovados devidamente identificados.

4.4 CONTROLE DE QUALIDADE DO PRODUTO FINAL:

4.4.1 Existência de controle de qualidade do produto final.

4.4.2 Existência de programa de amostragem para análise laboratorial do produto final.

4.4.3 Existência de laudo laboratorial atestando o controle de qualidade do produto final, assinado pelo técnico da empresa responsável pela análise ou expedido por empresa terceirizada.

4.4.4 Existência de equipamentos e materiais necessários para análise do produto final realizadas no estabelecimento.

4.5 TRANSPORTE DO PRODUTO FINAL:

4.5.1 Produto transportado na temperatura especificada no rótulo.

4.5.2 Veículo limpo, com cobertura para proteção de carga. Ausência de vetores e pragas urbanas ou qualquer evidência de sua presença como fezes, ninhos e outros.

4.5.3 Transporte mantém a integridade do produto.

4.5.4 Veículo não transporta outras cargas que comprometam a segurança do produto.

4.5.5 Presença de equipamento para controle de temperatura quando se transporta alimentos que necessitam de condições especiais de conservação.

\section{DOCUMENTAÇÃO}

\subsection{MANUAL DE BOAS PRÁTICAS DE FABRICAÇÃO:}

5.1.1 Operações executadas no estabelecimento estão de acordo com o Manual de Boas Práticas de Fabricação.

\subsection{PROCEDIMENTOS OPERACIONAIS PADRONIZADOS:}

5.2.1 Higienização das instalações, equipamentos e utensílios:

5.2.1.1 Existência de POP estabelecido para este item. 
5.2.1.2 POP descrito está sendo cumprido.

5.2.2 Controle de potabilidade da água:

5.2.2.1 Existência de POP estabelecido para controle de potabilidade da água.

5.2.2.2 POP descrito está sendo cumprido.

5.2.3 Higiene e saúde dos manipuladores:

5.2.3.1 Existência de POP estabelecido para este item.

5.2.3.2 POP descrito está sendo cumprido.

5.2.4 Manejo dos resíduos:

5.2.4.1 Existência de POP estabelecido para este item.

5.2.4.2 O POP descrito está sendo cumprido.

5.2.5 Manutenção preventiva e calibração de equipamentos.

5.2.5.1 Existência de POP estabelecido para este item.

5.2.5.2 O POP descrito está sendo cumprido.

5.2.6 Controle integrado de vetores e pragas urbanas:

5.2.6.1 Existência de POP estabelecido para este item.

5.2.6.2 O POP descrito está sendo cumprido.

5.2.7 Seleção das matérias-primas, ingredientes e embalagens:

5.2.7.1 Existência de POP estabelecido para este item.

5.2.7.2 O POP descrito está sendo cumprido.

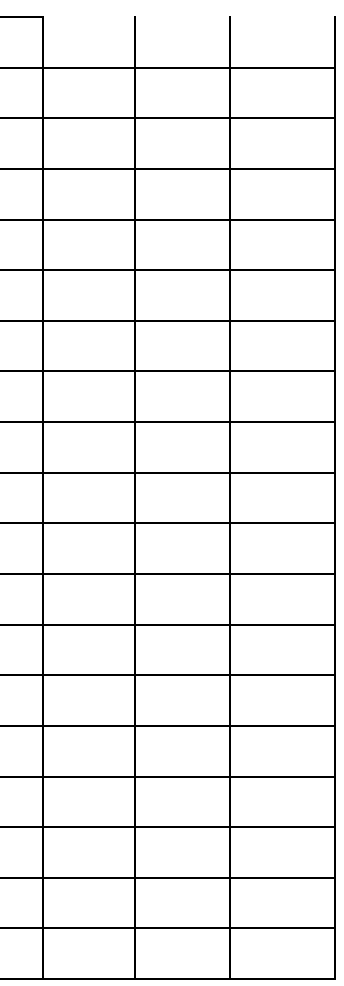

B - AVALIAÇÃo

5.2.8 Programa de recolhimento de alimentos:

5.2.8.1 Existência de POP estabelecido para este item.

5.2.8.2 O POP descrito está sendo cumprido.

SIM NÃO NA(*)

- CONSIDERAÇÕES FINAIS 

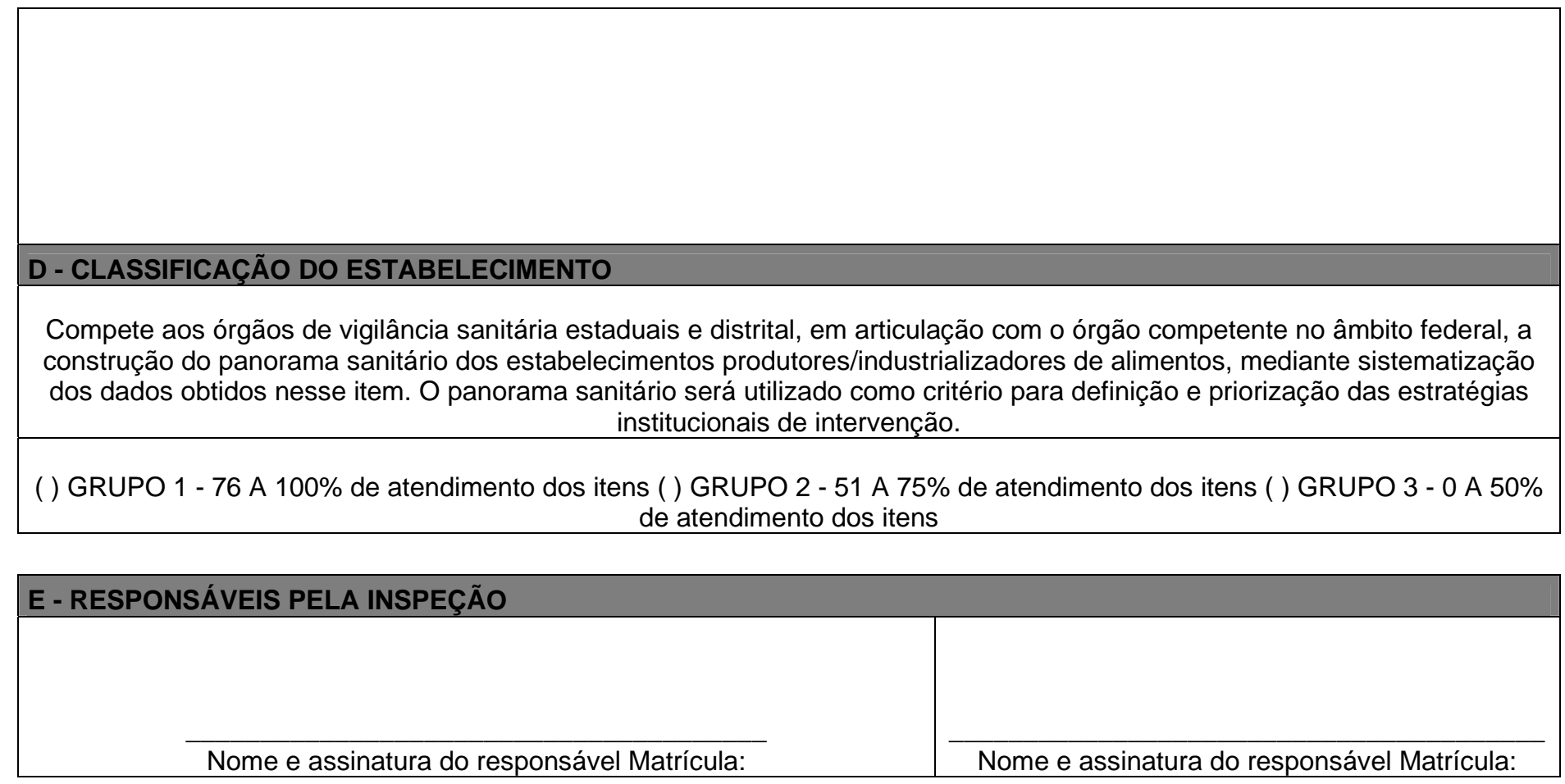

\section{F - RESPONSÁVEL PELA EMPRESA}

Nome e assinatura do responsável pelo estabelecimento

\begin{tabular}{|l|l|}
\hline LOCAL: & DATA: _ I _ I _ \\
\hline
\end{tabular}

